\title{
Ibsen's “A Doll's House” as a Psychological Trust Game with Guilt and Reciprocity
}

\author{
Fabienne Oguer \\ University of Franche-Comte \\ U.F.R. S.J.E.P.G., 25030 Besançon Cedex, France \\ E-mail: fabienne.oguer@univ-fcomte.fr
}

\begin{abstract}
From a game-theoretic point of view, "A Doll's House" displays a trust game. A classic game-theoretic approach enables us to model the behavior of the characters, but it does not suffice to explain it since the backward induction solution of the game does not correspond to their decisions in the story. A psychological game-theoretic approach helps to explain the choices for it takes into account guilt aversion and reciprocity considerations.
\end{abstract}

Keywords: Ibsen, Psychological game, Trust, Guilt, Reciprocity

\section{Introduction}

Ibsen's famous play “A Doll's House” (1879), drawn from a genuine news item, is often performed and adapted for the screen. From a sociological point of view, it deals with women's rights and duties. It is the starting point of research in the domain of family psychotherapy (Flomenhaft \& Pittman, 2004). Alternatively, a game-theoretic approach highlights a marital partnership with trust, where the possibility of guilt aversion or reciprocity considerations explains the characters' behavior.

The story takes place in the $19^{\text {th }}$ century. Nora Helmer is a middle-class housewife who has started a family with a lawyer named Torvald. They met when, at the Ministry, Torvald conducted an investigation into Nora's father and helped him to keep his job. At the beginning of her married life, Nora needed 250 pounds to finance a trip to Italy that would restore Torvald to health. Since her father is dying and she doesn't want to worry him, and since Torvald refuses to take out a loan, she borrowed the money secretly from an unscrupulous man, Nils Krogstad, also a lawyer. As a married woman, she cannot take out a loan without her husband's consent, so she writes her father to secure her debt, and forges his signature. Because she had acted clumsily, Krogstad realized the hoax, but Nora did not realize that her misdeed had been unmasked.

The play itself starts eight years later. Torvald will soon be the manager of the Bank, and Krogstad will be his subordinate. When Nora's childhood friend settles in town, Torvald, at Nora's request, agrees to recruit her. However, he decides to dismiss Krogstad, as he has a bad opinion of his moral character and he thinks that he is too familiar with him. Krogstad tries to blackmail Nora, to make her persuade Torvald to allow him to keep his place at the Bank, even to improve his social position. Because she fails, Krogstad reveals her misdeed to Torvald, who realizes that he may lose his reputation, and so forbids her to look after their children. He lifts this punishment when, at the request of Nora's childhood friend, Krogstad gives them back the IOU. Nevertheless Nora decides to leave her marital home since she thinks that she has lived her marriage as if in a doll's house.

This article is concerned with Torvald's and Nora's choices at the beginning of the story. It models their behavior by means of a trust game in which Torvald trusts Nora when, closing his eyes to her father's faults, he marries her, and Nora betrays his trust when she takes the loan against his will.

A benchmark model of trust is presented in Kreps (1990). This is similar to the partnership game discussed in Rabin (1993), to the investment game analyzed by Berg, Dickhaut, and McCabe (1995) and to Dufwenberg's (2002) study of a married couple's educational investment. According to Kreps, the trust game is a one-sided version of the prisoners' dilemma game. It is a two-period and two-player game where individual A plays first, taking the irreversible decision to trust or not to trust individual B. If he does not trust her, the game has no second period. If he trusts her, she may or may not honor his trust. It is in her interest to betray his trust, in which case it would be better for him not to trust her. The dilemma-type of this backward induction solution 
(Dufwenberg \& Güth, 2004) results from the fact that it would be better for both players if he trusts her, and that she honors his trust.

This article shows that such a classic game-theoretic analysis can shed new light on the behavior of the characters in "A Doll's House" but that it is insufficient to explain it. Indeed Torvald chooses to trust Nora because he believes that she is guilt averse or that she has reciprocity considerations. The article employs a psychological game-theoretic analysis to model their choices. Geanakoplos, Pearce, and Stacchetti (1989) have developed the framework of psychological games and Battigalli and Dufwenberg (2009) have extended it. According to Geanakoplos et al., such an approach enables one to analyze belief-dependent considerations in situations where gains are defined not only on choices, but also on the hierarchy of a player's beliefs about choices.

In the psychological trust game player B chooses to honor player A's trust if by deceiving him she feels guilty. As Dufwenberg and Güth (2004) define it, in the classic game guilt is intrinsic, since a player feels guilty because he deceives another player; in a psychological game, guilt is belief-dependent, since the player feels guilty because he believes that the other player believes he will not deceive him. According to Dufwenberg (2002, 2008), the more a guilt-averse player disappoints another player's expectations, the stronger he feels guilty.

In the psychological trust game, B may also choose to honor A's trust, if she has reciprocity considerations. Rabin (1993) introduces such a fairness motivation. According to Rabin, and Dufwenberg and Kirchsteiger (2004), this motivation appears when a player adopts a kind (unkind) behavior in response to a kind (unkind) action.

Section 2.1 models the story as a classic trust game. It presents a Nash equilibrium and shows that this solution of the game does not explain the choice of both characters in the story. Section 2.2 introduces the possibility that Nora feels guilt aversion. It shows that the psychological trust game may explain Torvald's decision to trust her. Moreover, introducing a chance move that determines initially if Nora is guilt averse, sustains the outcome in which Torvald trusts Nora and she betrays his trust. Section 2.3 similarly explains Torvald's decision to trust Nora, when he believes that she has reciprocity considerations. Section 3 concludes.

\section{The trust game in "A Doll's House"}

\subsection{The classic trust game}

A game takes place at the beginning of the story. Before his marriage to Nora, Torvald was employed by the Ministry to investigate Nora's father. He prevented him from being dismissed: "Your father was not a man of unassailable reputation" (Act 2). So he is aware that she can be dishonest, capable of making the same mistakes as her father. Nevertheless, he decides to close his eyes to the father's faults and to marry her.

When Nora needs money to finance their trip to Italy, she knows that he is opposed to taking out a loan: "he got almost angry with me ... he said I was frivolous" (Act 1). Nevertheless, she prefers to commit a forgery and take the loan as she wishes above all that her father be unaware of her husband's illness. Before Torvald learns of her misdeed, Nora had even believed that in the future she held an advantage: "He's frightfully strict about such matters. And besides - he's so proud of being a man - it'd be so painful and humiliating for him to know that he owed something to me" (Act 1). She thinks of telling him, "Years from now, when I'm no longer pretty ... Then it might be useful to have something up my sleeve" (Act 1).

Therefore the situation presents a trust game. Torvald chooses between "Trust" (T) or "No trust" (N), since he may marry Nora and close his eyes to her father's faults, or not. Nora chooses between "Honor" (H) or "Betray" (B), since she may ask her father for money, or take the loan against Torvald's will. Let $0,1 / 2$ and 1 be Torvald's and Nora's possible gains according to their choices. When Torvald plays Trust, his gain is 1 if Nora plays Honor, or 0 if she plays Betray. When he plays No trust, he obtains an intermediate gain of $1 / 2$. Conversely, Nora's gain is 1, when Torvald plays Trust and she plays Betray; on the other hand her gain is 0 , when he plays No trust. She obtains an intermediate gain of $1 / 2$, when Torvald plays Trust and she plays Honor.

The extensive form and the equilibrium path of this two-player dynamic game with complete information are presented in figure 1. Its (subgame perfect) Nash equilibrium is (No trust, Betray), where Torvald does not close his eyes to the faults of Nora's father, he does not marry Nora and (provided Torvald trusts her) Nora takes the loan against his will. It is inefficient since (Trust, Honor) payoff-dominates it. This backward induction solution of the classic trust game does not explain why Torvald and Nora play (Trust, Betray) in the first place. 


\subsection{The psychological trust game with guilt aversion}

In the story, what motivates Torvald to play Trust may be that he believes Nora would feel guilty if she betrayed his trust. Therefore a psychological game approach is necessary to model their choices. In such a framework, as Geanakoplos et al. (1989) develop it, a player's gain depends on his choice, his beliefs about the other players' choice and his beliefs concerning the other players' beliefs about his choice.

Suppose first that Nora actually has feelings of guilt. Let $q$ be the probability that she plays Honor; let $r$ be Torvald's belief about the probability q; let $\mathrm{s}$ be Nora's belief about Torvald's expectation $\mathrm{r}$ of her choice q. According to Dufwenberg (2002), the more she believes he trusts her, the more guilty she feels when she betrays his trust and her gain is reduced. Therefore, Nora's gain, if Torvald plays Trust and she plays Betray, is $1-\mathrm{s}$.

The extensive form of this psychological trust game with guilt aversion is presented in figure 2. At psychological Nash equilibrium, each player maximizes his gain given beliefs that must be correct (Geanakoplos et al., 1989). It follows from Dufwenberg and Güth's (2004) results that this psychological trust game with guilt aversion has two equilibriums. In the first, $\mathrm{q}=\mathrm{r}=\mathrm{s}=0$, so that the equilibrium strategies are $(\mathrm{N}, \mathrm{B})$ as in the classic trust game. In the other one $\mathrm{q}=\mathrm{r}=\mathrm{s}=1$ and the equilibrium strategies are $(\mathrm{T}, \mathrm{H})$. The second equilibrium explains Torvald's decision to trust Nora, but none of the equilibriums of the psychological trust game with guilt aversion explains the course of the story. Indeed, Nora feels no guilt aversion. When Krogstad reveals her misdeed to Torvald, the latter understands that she has no scruples: "I ought to have guessed that something of this sort would happen. I should have foreseen it. All your father's recklessness and instability ... he has handed on to you! ... Oh, how I have been punished for closing my eyes to his faults! I did it for your sake. And now you reward me like this" (Act 3).

Following Dufwenberg and Güth's (2004) approach, suppose now that in the trust game a chance move decides initially if a player feels guilt aversion, or not. Let $\mathrm{p}$ be the probability that Nature chooses "Guilt aversion" for Nora's type; $1-\mathrm{p}$ is the probability that Nora's type is "No guilt aversion".

The psychological trust game with incomplete information about Nora's guilt aversion is presented in figure 3 . In this game, Torvald knows the a priori probability $\mathrm{p}$, but he does not know exactly what Nora's type is. Therefore, he does not know which node is reached in his information set. This set collects together the two decision nodes for Torvald at which he plays after Nature has chosen Nora's type. The game that begins at the left-hand node is the psychological trust game with guilt aversion; at the right-hand node, it is the classic trust game.

Applying Dufwenberg and Güth's (2004) results, such a psychological trust game with incomplete information has two equilibriums. In the first one, (N, B B), Torvald does not trust Nora and, if he trusted her, she would take the loan whatever her feelings are about guilt. The second one, (T, H B), exists if $p>1 / 2$; the equilibrium path is presented in figure 3. In this equilibrium, Torvald thinks that Nora is probably guilt averse, so he trusts her; she betrays his trust in the case where she has no guilt aversion. This outcome corresponds to the characters' choices in the story.

\subsection{The psychological trust game with reciprocity considerations}

What also motivates Torvald when he plays Trust may be his belief that Nora will have reciprocity considerations if he trusts her. According to Rabin (1993), a player that has reciprocity considerations helps (punishes) a kind (unkind) player, and a psychological game approach enables one to incorporate such fairness motivations into the players' behavior. In Rabin's study, and in Dufwenberg and Kirchsteiger's (2000, 2004) approach, a player's gain takes into account his kindness to the other player, and his belief about how kind the other player is to him.

Applying Dufwenberg and Kirchsteiger's (2004) study, consider Torvald's decision to prevent Nora's father from being dismissed and to marry her, although he is aware that, should the need arise, she could be just as dishonest as her father. Torvald's action is kind, whatever he believes Nora will choose. Indeed, if he believes that Nora will choose Betray with probability one, he believes that her gain will be higher than if he chooses No trust (if he trusts Nora, her gain will be 1 , and 0 if he does not). Similarly, if he believes that Nora will choose Honor, he believes that it will be better for her than if he chooses No trust (her gain will be $1 / 2$ instead of 0 ).

Suppose that Nora actually has reciprocity considerations. Then, if she believes that Torvald is kind (unkind) to her, she wants to be kind (unkind) in return. If he trusts her, a kind behavior for Nora is to play Honor. Therefore, if she has reciprocity motivations she does not take the loan against his will.

Applying Dufwenberg and Kirchsteiger's (2004) result, (Trust, Honor) may be an equilibrium of the psychological trust game with reciprocity considerations. This equilibrium explains Torvald's decision to trust 
Nora, but it does not explain the course of the story. Indeed, Nora betrays his trust since she has actually no reciprocity motivations.

\section{Concluding remarks}

This article shows that from a game-theoretic point of view, "A Doll's House" displays a trust game where Torvald trusts Nora and she betrays his trust. A classic game-theoretic approach does not suffice to explain the behavior of these characters, since the backward induction solution of the game does not correspond to their decisions in the story. Therefore, the article resorts to a psychological game-theoretic approach to model Torvald's and Nora's choices. Torvald's belief that Nora is guilt averse or that she has reciprocity considerations explains his choice to trust her. Moreover, introducing a chance move into the trust game, one that initially decides Nora's type, enables us to explain the choices of both characters in the play. If Torvald thinks that Nora is probably guilt averse, then there exists an equilibrium reflected in the story, since he trusts her and she does not honor his trust.

In Dufwenberg's (2002) study of a marital partnership, roles are reversed. Two spouses choose the one who will make an investment in schooling, while the other one will support the household. The resulting revenue is higher in the case of the husband's investment. The wife plays first, taking the irreversible decision of giving up her studies or working her way up. If she trusts her husband and gives up her studies, he may exploit her trust, getting divorced once he has a very good position, to keep his entire high revenue. He too may reward her trust, sharing this high revenue. At the Nash equilibrium strategies of this trust game, the wife does not trust her husband and works her way up; if she trusts him and gives up her studies he exploits her trust and gets divorced. Incorporating guilt aversion in this trust game, Dufwenberg finds psychological equilibriums depending on guilt sensitivity.

The trust game is the subject of experimental studies. For instance, Berg et al. (1995) verify the existence of reciprocity considerations in their investment game and Bacharach, Guerra, and Zizzo (2001) test whether trust is fulfilled because of the belief of the player that he is trusted.

In most literary works such as in "A Doll's House", a game-theoretic approach may help to understand the behavior of the characters. Brams (1994) presents fictional situations where a classic game-theoretic analysis sheds a new light. In Deloche and Oguer (2006), game theory enables the analysis of Poe's detective work, as well as an analysis of some episodes in his life.

In real contexts, as in fictional ones, psychological game theory may enable us to model strategic situations where players have to make belief-dependent acts. For instance, Dufwenberg and Kirchsteiger (2000) investigate employer-employee relationship when workers are motivated by reciprocity; Regner and Barria (2009) explain experimentally the voluntary payment behavior of the customers of an online music label.

\section{References}

Bacharach, M., Guerra, G., \& Zizzo, D. J. (2001). Is trust self-fulfilling? An experimental study. Unpublished manuscript, University of Oxford, Department of Economics, Discussion Paper $n^{\circ} 76$.

Battigalli, P., \& Dufwenberg, M. (2009). Dynamic psychological games. Journal of Economic Theory, 144, $1-35$.

Berg, J., Dickhaut, J., \& McCabe, K. (1995). Trust, reciprocity, and social history. Games and Economic Behavior, 10, 122-142.

Brams, S. J. (1994). Game theory and literature. Games and Economic Behavior, 6, 32-54.

Deloche, R., \& Oguer, F. (2006). Game theory and Poe's detective stories and life. Eastern Economic Journal, 32, 97-110.

Dufwenberg, M. (2002). Marital investments, time consistency and emotions. Journal of Economic Behavior and Organization, 48, 57-69.

Dufwenberg, M. (2008). Psychological games. In S. N. Durlauf, \& L. E. Blume (Eds.), The New Palgrave Dictionary of Economics (2nd ed.). London: Palgrave Macmillan.

Dufwenberg, M., \& Güth, W. (2004). The psychological game of trust. Unpublished manuscript, University of Arizona, \& Max Planck Institute for Research into Economic Systems.

Dufwenberg, M., \& Kirchsteiger, G. (2000). Reciprocity and wage undercutting. European Economic Review, 44, 1069-1078. 
Dufwenberg, M., \& Kirchsteiger, G. (2004). A theory of sequential reciprocity. Games and Economic Behavior, 47, 268-298.

Flomenhaft, K., \& Pittman, F. S., III. (2004). Treating the Doll's House marriage. Family Process, 9, 143-155.

Geanakoplos, J., Pearce, D., \& Stacchetti, E. (1989). Psychological games and sequential rationality. Games and Economic Behavior, 1, 60-79.

Kreps, D. (1990). Corporate culture and economic theory. In J. E. Alt, \& K. A. Shepsle (Eds.), Perspectives on positive political economy (pp. 90-143). Cambridge: Cambridge University Press.

Rabin, M. (1993). Incorporating fairness into game theory and economics. American Economic Review, 83, 1281-1302.

Regner, T., \& Barria, J. A. (2009). Do consumers pay voluntarily? The case of online music. Journal of Economic Behavior and Organization, 71, 395-406.

\section{Figures}

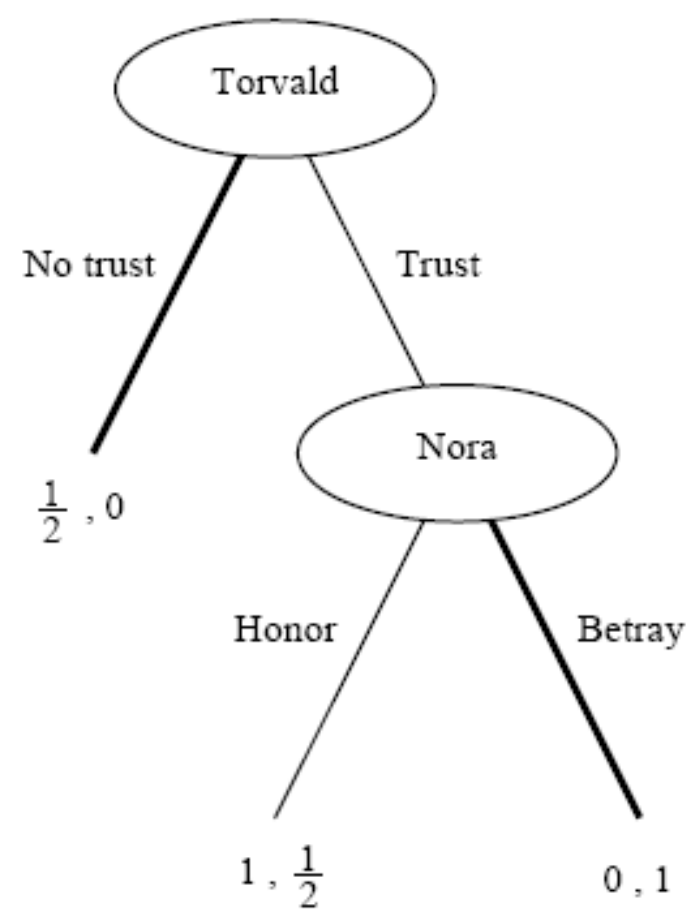

Figure 1. The classic trust game and its equilibrium path 


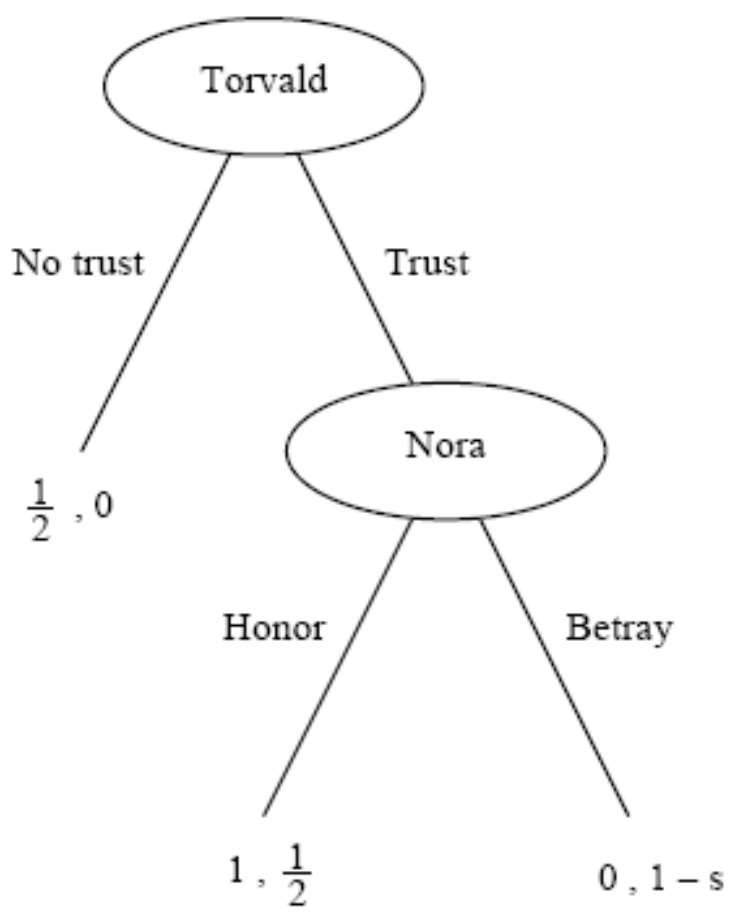

Figure 2. The psychological trust game with guilt aversion 


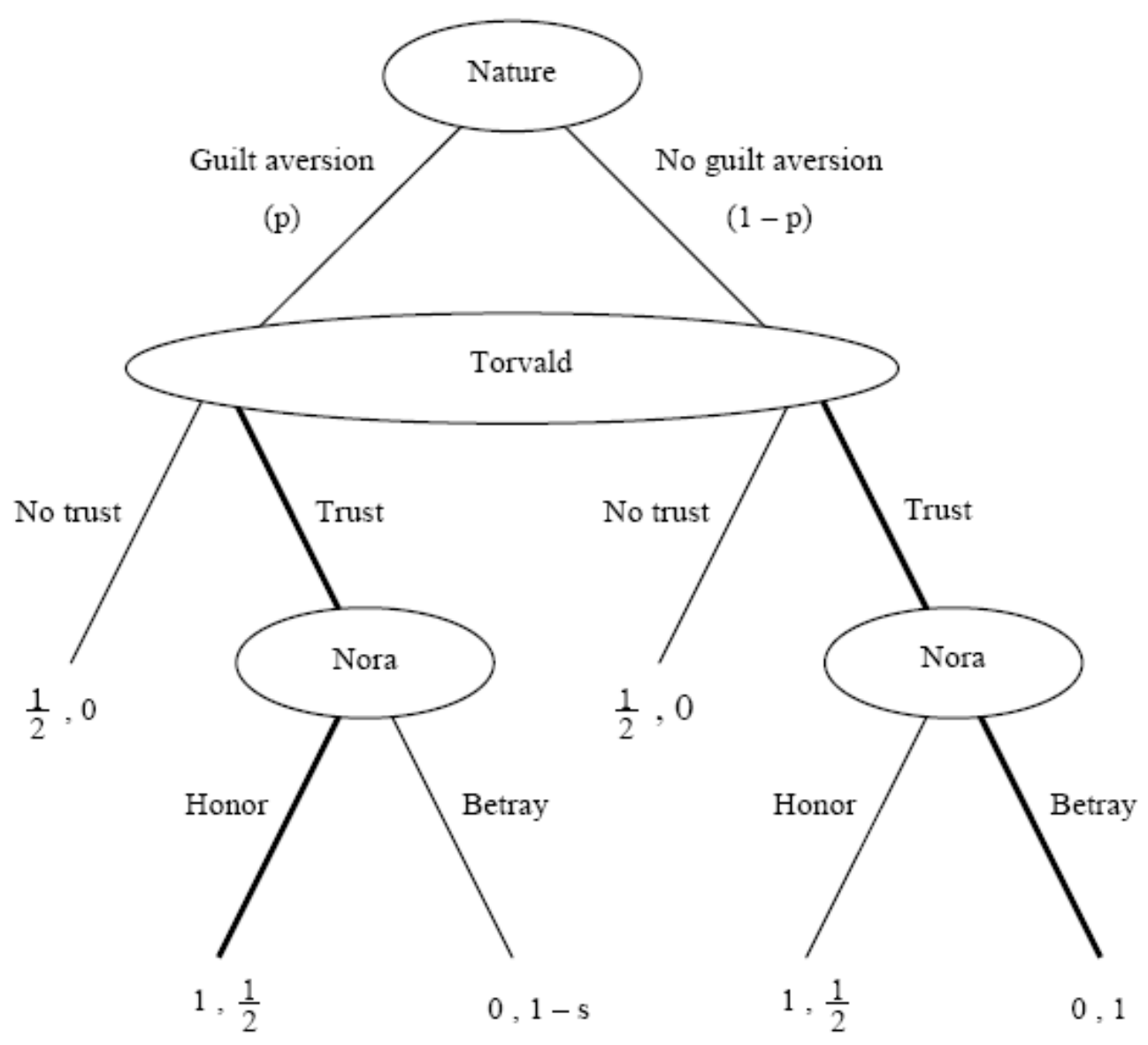

Figure 3. The psychological trust game with incomplete information about Nora's guilt aversion and its equilibrium path for $p>1 / 2$ 